\title{
Educação e práticas contemporâneas de visualidade: o que significa, afinal, ensinar pela cultura visual
}

\author{
Juliana Zanini Salbego * \\ Leonardo Verde Charréu **
}

\section{Resumo}

O presente texto tem por objetivo continuar uma discussão sobre as relações possíveis entre os campos da educação e da cultura visual, sugerindo um viés que sistematize uma espécie de epistemologia da cultura visual. Para isso, utilizamos como eixo argumentativo a ideia de um ensino pela cultural visual, em oposição ao que seria um ensino da cultura visual, construindo, a partir deste termo, três enunciados: de que a cultura visual é um campo transdisciplinar e, portanto, não pode ser ensinado como um conjunto fechado de conteúdos; que a cultura visual pode ser entendida como um tipo de estratégia para interligar os conteúdos da escola ao cotidiano extraescolar dos alunos; por fim, um manifesto em defesa de uma educação pela cultura visual. Para embasar tais discussões e proposições, lançamos mão das perspectivas teóricas de autores como Hernández (2000, 2005, 2007); Freedman (2006); Mirzoeff (2003); Eisner (2008); dentre outros.

Palavras-chave: Educação. Cultura Visual. Imagem. Visualidade.

* Doutora em Educação pela Universidade Federal de Santa Maria (UFSM). Professora do Curso de Publicidade e Propaganda da Universidade Federal do Pampa (UNIPAMPA), Campus São Borja.

* Doutor em Ciências da Educação pela Universidade de Évora (EU), Portugal. Professor do Departamento de Educação em Línguas, Comunicação e Artes, da Escola Superior de Educação (ESELx) do Instituto Politécnico de Lisboa, Portugal. 


\section{Introdução}

Parecem pertencer hoje ao senso comum um conjunto de frases e afirmações que surgem, insistentemente, nas mais variadas áreas sociais e culturais. Uma delas, tão óbvia quanto clarividente, considerando o peso que as imagens têm no nosso cotidiano, destaca-se de entre todas as outras: a experiência humana é, a cada dia que passa, cada vez mais visual. Um conhecido autor, Nicholas Mirzoeff, do âmbito dos estudos de cultura visual, acrescentou até que essa experiência contemporânea é mais visual e "mais visualizada" (MIRZOEFF, 2003, p.18), o que infere uma intencionalidade de alguém mostrar algo e pressupõe uma vontade ou um desejo de outro alguém ver.

Autores como Gillian Rose (2001) sustentam que o nosso uso das imagens e a nossa apreciação de certos tipos de iconografias performatizam tanto uma função estética, quanto uma função social, dizendo sobre quem somos e como desejamos ser vistos. Em certa medida, somos como nos mostramos e isso pode levar-nos a instigantes derivas teórico-especulativas nos âmbitos da identidade e da subjetividade, que não são bem os objetivos deste nosso texto. Estas constatações axiomáticas ou enunciadoras levam, consequentemente, à necessidade de nos conscientizarmos sobre o fato de que o entendimento acerca das práticas de visualidade, bem como dos artefatos e das tecnologias visuais que permeiam nosso cotidiano, torna-se hoje imprescindível, especialmente no âmbito da educação pública formal.

Para outros autores, como Camile Paglia (2014), esta nova condição deste nosso tempo, definido por uns (LYOTARD, 1979) como pós-modernidade, por outros como modernidade tardia (GIDDENS, 1991, CASTELLS, 2000), por outros, ainda, como modernidade "líquida" (BAUMAN, 2001), é uma ameaça.

A vida moderna é um mar de imagens. Nossos olhos são inundados por figuras reluzentes e blocos de texto explodindo sobre nós por todos os lados. O cérebro, superestimulado, deve se adaptar rapidamente para conseguir processar esse rodopiante bombardeio de dados desconexos. A cultura no mundo desenvolvido é hoje definida, em ampla medida, pela onipresente mídia de massa e pelos aparelhos eletrônicos servilmente monitorados por seus proprietários. A intensa expansão da comunicação global instantânea pode ter concedido espaço a um grande número de vozes individuais, mas, paradoxalmente, esta mesma individualidade se vê na ameaça de sucumbir. (PAGLIA, 2014, p.VII). 
No entanto, paradoxalmente, numa era cujo desenvolvimento e democratização do acesso aos aparatos visuais para visualização e realização de imagens atingiu níveis impensáveis há bem poucos anos, parece ter chegado um momento em que necessitamos de reaprender a ver como forma de "sobrevivência", como preconiza Camile Paglia (2014) na introdução da sua obra:

Como sobreviver nesta era da vertigem? Precisamos reaprender a ver. Em meio à tamanha e neurótica poluição visual, é essencial encontrar o foco, a base da estabilidade, da identidade e da direção na vida. As crianças, sobretudo, merecem ser salvas deste turbilhão de imagens tremeluzentes que as viciam em distrações sedutoras e fazem a realidade social, com seus deveres e preocupações éticas, parecer estúpida e fútil. A única maneira de ensinar o foco é oferecer aos olhos oportunidades de percepção estável [...]. (PAGLIA, 2014, p. VII).

Esta autora propõe a apreciação da arte "oficial" contida e circunscrita diligentemente pela disciplina de história da arte, adotando um tom salvífico e prescritivo como uma das formas de responder a esse mundo caótico sob bombardeio constante e sistemático.

\section{Sob bombardeamento imagético: uma característica da contemporaneidade}

Esta ideia de bombardeio é teorizada de forma diferente por Jennifer Eisenhauer (2006, p. 156), que define uma linguagem do bombardeio em que é tecida a relação entre o observador e o observado. Estas repetidas referências ao bombardeio, sobretudo a partir de mensagens dos media, onde a presença da imagem é onipresente, constitui-se para esta autora como discurso, no qual a tendência assinalada é para manter dicotomias ativas/passivas entre sujeitos e objetos.

Em face desta nova condição social, cultural e civilizacional, a escola continua ancorada nas velhas narrativas, práticas e tradições. Daí o aparente (ou real!) divórcio crescente entre os jovens e os seus processos de escolarização. As imagens do presente são tudo o que querem dissecar, desmontar, interpretar e compreender, contudo o que a escola lhes dá ainda, em geral, são imagens de um passado distante.

Ao falarmos de cultura visual estamos pisando em um terreno ainda bastante arenoso, uma vez que nos referimos a estudos que emergiram, de acordo com o que nos revela Hernández (2007), no final dos anos 1980, em um debate que entremeia discussões de áreas diversas como a cultura dos media, a história da arte, estudos da sociologia da cultura, da área do cinema, da linguística, dos 
estudos culturais, entre outros. A perspectiva comum a estas áreas é apontar o rumo em direção a um novo paradigma que aponta para a necessidade de investigação da postura subjetiva dos sujeitos com relação ao consumo dos artefatos simbólicos que se manifestam visualmente. Em outras palavras, significa dizer que, de acordo com o que aponta Hall (1997) sobre o conceito de "representação", as coisas não tem nenhum significado em si, a priori, mas este é constituído coletivamente a partir dos sistemas de linguagem que cada cultura elabora em cada momento histórico. Esta perspectiva nos leva a considerar o significado menos em termos de certeza e verdade e mais em termos de troca - um processo de intercâmbio que sempre leve em conta a persistência da diferença e das relações de poder entre os distintos sujeitos dentro de um mesmo circuito cultural.

Tal perspectiva confere à cultura visual um enorme potencial crítico, com profundo alcance educacional. Sobretudo se pensarmos o espaço escolar não mais como o lugar de repetição e recognição, mas antes como um lugar de posicionamentos críticos ativos, de debate e de construção coletiva do conhecimento, tendo como base as micronarrativas que permeiam o cotidiano. Neste tipo de pensamento crítico, ocorre uma importante mudança: o espectador/leitor, que tradicionalmente era considerado como uma receptáculo passivo da informação cultural, passa a ser tão importante quanto o produtor da imagem/texto no processo de leitura e construção dos significados.

Partindo desta perspectiva, o termo cultura visual refere-se, segundo Hernández (2007, p. 22), a

[...] uma diversidade de práticas e interpretações críticas em torno das relações entre as posições subjetivas e as práticas culturais e sociais do olhar. [...] movimento cultural que orienta a reflexão e as práticas relacionadas a maneiras de ver e de visualizar as representações culturais e, em particular, refiro-me às maneiras subjetivas e intrasubjetivas de ver o mundo e a si mesmo.

De acordo com o pensamento de Mirzoeff (2003), que já sublinhamos no início deste texto, segundo o qual, hoje, a experiência humana é cada vez mais visual e visualizada, principalmente em função do desenvolvimento acelerado das tecnologias, que nos fornecem todo o tipo de imagens, desde produtos via satélite (com um alcance global) até imagens do interior do corpo humano (enfatizando o aspecto mais micro e particular do ser humano). Significa dizer que as imagens passaram a constituir a vida dos sujeitos de uma maneira muito mais intensa. Podemos até dizer que o fenômeno selfie é uma emergência desta captura do cotidiano da imagem individual, uma necessidade quase patológica de registo dessa imagem que, em regra, é depois socializada, difundida imediatamente nas redes sociais da 
internet. Neste panorama, o que se põe como imperativo é a discussão sobre a relação que os sujeitos estabelecem com estas imagens: como é que as imagens nos atingem? Que usos fazemos delas e como é que elas interferem nas nossas relações e nas maneiras de nos constituirmos como sujeitos e de nos relacionarmos com os demais? Que imagens são estas? O que é que as imagens representam para nós? De que maneira as imagens transformam/constituem as nossas vidas?

O campo da cultura visual propõe, atualmente, uma extensa gama de discussões e questionamentos a este respeito. Em verdade, a nossa relação com as imagens mudou muito em função do desenvolvimento acelerado das tecnologias, o que suscitou também o surgimento de novas práticas sociais em relação à visualidade, entendida como uma ação de ver em contexto cultural. Um ver consciente das várias influências e pressões que ele mesmo exerce sobre o observador. É fundamental acentuar que uma área importante do campo da cultura visual está diretamente ligada à expansão daquilo que é/foi considerado arte e sofreu grandes transformações, especialmente a partir das vanguardas do final do século XIX e início do século XX. Tais vanguardas, plurais em pensamento, número e localização no mundo, passaram não só a questionar o estatuto da arte mas também a flexibilizar e movimentar as linguagens, os objetivos e os materiais utilizados nas produções da época. Podemos apontar, por exemplo, o nascimento das práticas do design gráfico em seus primórdios, com os desenhos de cartazes feitos pelo pintor francês Henri de Toulouse-Lautrec, ao final do século XIX, para a divulgação de shows nos cabarés da Belle Époque francesa. Nascia aqui, em conjunto com as práticas artísticas dos primórdios do movimento Art Nouveau, alguns dos primeiros cartazes e posteres publicitários (nos moldes mais contemporâneos) e alguns dos fundamentos do design gráfico (PROENÇA, 2009).

De acordo com Proença (2009, p. 364), “à medida que a técnica e depois a tecnologia invadiram os meios de produção, acabaram provocando também o surgimento de novas formas artísticas nas quais foi ultrapassada a rígida separação entre obras de arte e objetos produzidos com a interferência de máquinas". A fotografia e o cinema são alguns dos exemplos mais significantes neste sentido. Quando Joseph Niépce trabalhou os primeiros experimentos da fotografia em 1826, inaugurava sem saber um novo paradigma da relação do homem com as imagens e com a realidade circundante. De repente (ainda com muitas limitações), o homem era capaz de captar um fragmento da realidade tal como ela se apresentava e visualizá-lo posteriormente. A partir da fotografia, logo em seguida ao cinema (com os 
Irmãos Lumiére, em 1895), constituía-se a ideia de "verdade" associada às imagens e intensificava-se o dito popular do "ver para crer". A exemplo disso, a chegada do homem à lua, no ano de 1969, televisionada mundialmente, causou comoção, e apenas tempos depois, sabendo-se das potencialidades de manipulação das imagens, é que se lançaram dúvidas sobre o real acontecimento. A relação que o homem estabeleceu com estes tipos de imagens, antes de completa crença, passou a ser, depois, de dúvida.

Hoje, mais de um século após a invenção da fotografia, a relação com as imagens mudou muito. As imagens passaram a ser questionadas sobre o que têm de explícito e, particularmente, sobre o que têm de implícito, isto é, sobre o que "deixaram de fora", por razões que se embasam em relações de poder (sustentadas por convicções religiosas, políticas, filosóficas, etc.) que circunscrevem todo processo de produção, circulação e experimentação (apreciação) de uma dada imagem.

As relações estabelecidas a partir dos processos artísticos na contemporaneidade também levam consigo tais implicações. Esta ideia está ligada a um princípio estético trabalhado recentemente por Nicolas Bourriaud (2009, p. 19-20), sobre a questão da estética relacional, na qual o autor propõe uma ideia de arte atualizada e modificada pelo princípio de intercâmbio:

A possibilidade de uma arte relacional (uma arte que tomaria como horizonte teórico a esfera das interações humanas e seu contexto social, mais que a afirmação de um espaço simbólico autônomo e privado) dá conta de uma mudança radical dos objetivos estéticos, culturais e políticos postos em jogo pela arte moderna.

O autor pondera sobre o contexto de intercâmbio ilimitado com o qual nos deparamos e a generalização das experiências de proximidade que vivemos na contemporaneidade.

De outro lado, o desenvolvimento tecnológico bem como a popularização e o fácil acesso, sobretudo pela internet, permitiram que as imagens estejam agora disponíveis à maioria da população mundial, especialmente nos países ocidentais e democráticos, mesmo as que pertencem a geografias longínquas. Neste novo paradigma, formado por uma espiral de imagens, "ver é mais importante que crer" (MIRZOEFF, 2003, p. 17).

A questão é que tais imagens dos mais diversos tipos - fotografias, desenhos, pinturas, imagens em movimento do cinema e da TV, especialmente a partir da internet - apresentam-se de tal forma em abundância que acabam naturalizando-se e sendo consumidas de maneira superficial, sem maiores investimentos interpretativos e críticos. Esta discussão leva-nos a questões como: qual o 
efeito/mudança que as imagens de uma determinada novela, por exemplo, causam nos sujeitos? De que maneira a representação da imagem da mulher-objeto, muito comum em publicidade de cerveja, perfumaria ou moda, por exemplo, incide na forma de nos vermos como mulheres? Como é que as representações do estereótipo de beleza da mulher magra, alta, de pele branca e cabelo liso, veiculadas em uma imensa quantidade de imagens nos media, em geral, afetam as maneiras de sentir e se relacionar dos jovens?

Mirzoeff (2003, p.18) afirma ainda que "a visualização da vida cotidiana não significa necessariamente que conhecemos o que observamos". A questão é que tudo se olha, mas o que se vê de verdade? "No que devemos crer se ver já não significa crer?” (MIRZOEFF, 2003, p. 18). Dessa forma, o que motiva as discussões em torno da cultura visual é também o paradoxo existente entre a abundância e riqueza da experiência visual e a capacidade de analisar esta observação (com mais ou menos profundidade), de fazer uso consciente dela.

Cabe salientar que uma das características fundamentais do campo da cultura visual é exatamente o esbatimento das fronteiras entre os diversos artefatos e práticas produzidas nos campos que se cruzam. Isso significa que as maneiras de consumo ou apropriação dos referidos objetos possuem, dentro da cultura visual, um igual peso, quer dizer, para um sujeito, a apropriação simbólica de um quadro de Picasso pode ter a mesma importância que a apropriação simbólica de um anúncio publicitário, tendo em vista que o que está em jogo não é o que este artefato "carrega consigo", mas a leitura que aquele sujeito faz deste artefato e como isso muda o sujeito consumidor. Assim, esta posição não significa a negação das diferenças qualitativas entre as imagens produzidas, no entanto aponta para uma outra maneira de pensar, aquela que entende o processo de experiência do sujeito com aquele produto como a questão mais relevante.

Segundo Dias (2011), um estudo pelo viés da cultura visual não significa uma exclusão sumária das artes de elite dos currículos, mas sim uma outra maneira mais relacional, inclusiva e menos hierárquica de integrá-las aos demais conteúdos de natureza transdisciplinar. Portanto fica evidente que os estudos em cultura visual não têm por objetivo "tomar o lugar" daqueles conteúdos mais ligados à estética e à história da arte mais tradicional, que são também muito importantes, mas, de outra forma, a tentativa é a de trabalhar em conjunto, ao lado, fazendo relações e destituindo as hierarquizações que inferiorizavam uma série de produtos da cultura. 
Esse possível destronamento do estético é uma ingênua projeção do medo que arte/educadores desenvolveram ao se aproximarem da ideia de cultura/arte como um conjunto de práticas, contrariamente ao estabelecido entendimento de que cultura/arte é um conjunto de obras. Mas, como vimos anteriormente, o objeto estético não perde o seu poder na cultura visual. Ele, simplesmente, é investido de outros poderes que o relacionam ao seu contexto social. (DIAS, 2011, p. 70).

Neste mesmo sentido, outro dos pontos importantes com relação aos estudos em cultura visual é o deslocamento que passa a ocorrer das grandes narrativas, da história oficial, para o cotidiano, do enfoque que se passa a dar às micronarrativas e junto com elas às experiências subjetivas dos alunos. Significa, ainda conforme Dias (2011), uma ênfase nas experiências diárias do visual e no deslocamento de sua atenção das belas artes para a visualização do cotidiano.

Camile Paglia (2014), embora falando, como já referimos atrás, a partir de uma postura apocalíptica, por um lado, e neoconservadora, por outro, de defesa da história da arte, enquanto disciplina a retomar e reconsiderar, sublinha que

[...] a cultura de massa é uma selva enfeitiçada na qual é fácil perder-se [...]. O jovem de hoje transpõe habilmente um denso turbilhão de relativismo e sincronicidade, o pop se autocanibaliza, com sua amostragem de grife e suas modas retrô, tornou-se uma estupenda superabundância, impossível de absorver e muitas vezes afastada por uma pose protetora de ironia nervosa. A ascensão dos medias sociais apagou as fronteiras entre público e privado e tudo ocupou com trivialidades telegráficas [...]. (PAGLIA, 2014, p. XVIII).

Todavia achamos que é precisamente a partir deste contexto que se revela a dimensão/importância da cultura visual na sociedade contemporânea, sobre o qual propomos uma discussão que busque contribuir nas maneiras pelas quais o campo da cultura visual pode e deve se relacionar com as práticas educativas. Não propondo, como Paglia, um regresso ao estudo da rígida sequencialidade e das grandes metanarrativas da história da arte, mas, ao invés, aceitando como "material de estudo" essas trivialidades (selfies, fotojornalismo, álbuns de família, telenovelas, publicidade, etc.) até há bem pouco tempo invisíveis e desconsideradas como conteúdo escolar. E se temos a educação como cenário de fundo, então é gerando um conjunto de perguntas, como as que se elencam abaixo, com as quais podemos almejar sair do engodo recognitivo e passivo com que somos envolvidos por algumas disciplinas escolares tradicionais.

Como é que a cultura visual se relaciona com a educação? De que maneira os processos de aprendizado estão relacionados com as imagens? O que pode a cultura visual fazer pela escola e vice- 
versa? Se a cultura visual é parte indissociável da vida dos sujeitos, não será indispensável tratá-la na escola? Desta maneira, este texto tem como objetivo apresentar uma contribuição em torno das discussões que relacionam a cultura visual e os processos de ensino.

Ao utilizar o termo pela, nós o fazemos com o objetivo de diferenciá-lo de um ensino da cultura visual, o que acarretaria sentidos opostos à argumentação que desenvolveremos a seguir. Na realidade, a nossa preferência pelo uso de uma contração (pela) sobre outra ( $d a$ ) tem importantes implicações conceituais. Com o uso da primeira contração, consideramos que ensinar pela cultura visual implica um escrutínio e sistematização do cotidiano imagético cultural que circunscreve a vida do aluno e sua concomitante problematização em sala de aula, requerendo uma postura ativa e participativa do aluno. Ao invés, o ensino da cultura visual, parece induzir a uma atitude mais aquisitiva e passiva por parte do aluno, que procura interpretar e entender um novo corpo de conhecimentos que, sendo bastante amplo e resolutamente crítico, pode eventualmente estar afastado daquilo que se pode chamar a sua experiência de mundo vivida.

Desta forma, o presente texto foi estruturado em três etapas, que desenvolverão a referida ideia, a saber: 1) o campo da cultura visual é transdisciplinar e não pode ser ensinado segundo os processos didáticos tradicionais; 2) a cultura visual pode ser pensada como uma estratégia; 3) um manifesto em prol da cultura visual em um mundo que oferece muitas opções alternativas.

\section{Educação pela cultura visual: um campo transdisciplinar que não pode ser tradicionalmente ensinado}

Conforme aponta Freedman (2006), o campo da cultura visual é transdisciplinar; ou, ainda nos termos usados por Hernández (2007), adisciplinar, o que significa entendermos que o referido campo de estudos não se constitui em um conjunto bem definido de conteúdos a serem ensinados. Ao invés disso, constitui-se do entrelaçamento de diversos outros, e não cabe no rigor de um campo disciplinar. Conforme comentamos no início de nosso texto, o campo da cultura visual é recente e constituído por conteúdos, discussões e problemáticas oriundas das mais diversas áreas, desde a história da arte, cultura da mídia, cinema, etc. Desta forma, seus estudos compreendem as mais variadas manifestações e produtos que envolvem a experiência visual que perpassa o cotidiano da nossa sociedade. O que há é 
um conjunto muito extenso, plural e mutante de mensagens visuais que atinge os estudantes diariamente e, de alguma forma, precisa ser levado em conta no momento de pensarmos as práticas de educação nas nossas escolas.

Para que possamos compreender melhor esta diversidade de formas e conteúdos que compõem o campo da cultura visual, lançaremos mão da metáfora do rizoma, cunhada por Deleuze e Guattari:

Os rizomas operam, primeiro, na base das conexões e homogeneidade, onde em lugar de universais existe uma série de dialetos, não um fazedor ideal nem uma audiência homogênea. Senão, em seu lugar, numerosos atores e comunidades. Os rizomas também funcionam sob os princípios de multiplicidade e ruptura, onde as conexões podem realizar-se a outra coisa, inclusive quando a conexão se rompe, a estrutura rizomática volta a renascer com um novo desenvolvimento ao longo das antigas linhas ou mediante a criação de novas linhas. Os rizomas não operam hierarquicamente a partir de um centro definido, senão que qualquer ponto do rizoma pode ser conectado com qualquer outro, ou deve sê-lo. (DELEUZE; GUATTARI, 1995, p. 15).

Assim, a metáfora do rizoma serve principalmente para apontar os princípios de conectividade e multidisciplinariedade, que compõem características importantes deste campo de estudo.

Conforme indica Hernández, há uma série de motivos para os quais se apresenta conveniente entender a cultura visual como um campo rizomático. É preciso enxergá-lo para muito além de algo linear e compacto, apresentando uma narrativa única. Diversamente, o campo entendido como rizoma possibilita a observação da multiplicidade de pontos de vista e valores disseminados nos produtos da cultura visual. Reitera o autor que

[...] no estudo da cultura visual é importante, por exemplo, prestar atenção à intercessão de raça, classe social, sexo e gênero nos meios visuais para poder elucidar e observar operações e formas de visualização e posicionamentos discursivos mais complexos. (HERNÁNDEZ, 2005, p. 11).

Podemos ainda pensar este campo como formado por dois elementos fundamentais, como o são: as formas culturais ligadas ao ato de ver, denominadas "práticas de visualidade" (HERNÁNDEZ, 2005); e o estudo amplo do rol de artefatos visuais que compõem a cultura-visual contemporânea, os quis abarcam produtos materiais e simbólicos que ultrapassam aqueles outrora reconhecidos pelo campo institucional da arte, como os produtos da cultura popular e da cultura dos media, por exemplo. Neste sentido, é importante sublinhar que entendemos a cultura visual a partir de uma perspectiva histórica, no entanto também consideramos que ela ultrapassa a mera atividade de catalogação e classificação de artefactos que na tradição histórica dá origem a uma escola, a uma corrente, a um 
movimento ou a um "ismo" qualquer. Ao invés, busca-se um estudo sobre os produtos visuais e as múltiplas experiências que interagem no interior e nas margens das práticas de visualidade. Em particular, presta-se uma cuidadosa atenção aos impactos que as imagens têm na formação das identidades e nas maneiras como essas imagens influenciam os modos de nos construirmos como sujeitos. Uma história da cultura visual não será, portanto, formada apenas pelos produtores dos artefatos visuais (e respectivo entesouramento museológico) mas também pelos processos de recepção destas formas visuais e as consequências disso no cotidiano social.

\section{Ensinar pela cultura visual: a cultura visual pode ser pensada como uma estratégia}

Há alguns anos, nos debates sobre a educação artística em Portugal (SANTOS, 2000; SOUSA, 2003), procurou-se conceitualizar os vários enfoques possíveis das conexões entre as duas grandes dimensões que formam este campo. Referimo-nos, evidentemente, às que circunscrevem a esfera da educação e da arte. Assim, nessa altura procurou-se distinguir claramente a Educação para a Arte, a Educação da Arte e a Educação pela Arte, sendo esta última uma perspectiva claramente influenciada pela obra emblemática Education Through Art, de Sir Herbert Read, publica em 1943.

O uso das contrações (destacadas em itálico) modifica conceitualmente essas perspectivas de ensino do visual. Uma Educação para Arte visaria, claramente, a jusante, a formação de futuros artistas, teria, portanto, um enfoque bem técnico, enquanto uma Educação da Arte apontaria para uma aquisição passiva ou uma recognição de conteúdos de natureza teórica-estética, historicista ou oficinal. Já Educação pela Arte pressuporia uma pedagogia mais aberta, permeável e resolutamente transdisciplinar. Significaria ensinar tendo geralmente a arte como pano de fundo, como elemento de tensionamento ou como elemento de experimentação de conteúdos e conceitos.

Então, neste texto, sugerimos a ideia de pensarmos a cultura visual como método ou estratégia. Se a cultura visual não é um campo disciplinar a ser ensinado com as práticas tradicionais expositórias da escola, mas, ao invés, constitui-se antes em uma confluência transversal de saberes de diversas áreas que perpassam densamente a vida da sociedade contemporânea e, especialmente, constituem, interagem e ajudam a formar os saberes, as experiências e as identidades de nossos jovens, parece legítimo que 
possamos ver então estes produtos como meios/pontes para interligarmos, de maneira dinâmica e contextualizada, os conteúdos escolares à vida dos alunos. Daí a segunda proposição de pensar o ensino pela cultura visual, e não da cultura visual. De maneira mais concreta, significa pensar as relações das produções imagéticas contemporâneas - como as da cultura dos media, por exemplo - como pontes de ligação entre os conteúdos escolares e a vida exterior à escola dos alunos. Sobretudo pensando a participação deles no processo de aprender.

No livro Catadores da Cultura Visual e também na obra Cultura Visual, Mudança Educativa e Projeto de trabalho, Hernández desenvolve uma metodologia interdisciplinar que procura, entre os seus muitos objetivos, integrar a cultura visual aos conteúdos a serem trabalhados na escola, de forma prática e interessante, a partir do desenvolvimento de projetos. Tais projetos têm por objetivo o desenvolvimento daquilo que este autor chamou de "uma outra narrativa para a educação", que seja mais autêntica, em busca de novos horizontes, "uma educação pensada a cada dia em conjunto com sujeitos em permanente transição rumo ao incerto e ao desconhecido e para os quais aprender de outras maneiras pode tornar-se uma experiência apaixonante" (HERNÁNDEZ, 2007, p. 17).

A partir desta perspectiva, propomos que o conjunto de experiências que poderão compor uma das aproximações possíveis à cultura visual e incidir cotidianamente nas maneiras pelas quais os docentes constroem as suas aulas, independentemente da disciplina. Hernández concorda com Popkewitz (1978) quando este diz que:

as disciplinas escolares são o resultado da alquimia reguladora que a instituição escolar exerce sobre os saberes culturais. Isso faz com o que se ensina na escola seja filtrado e selecionado, e costuma estar longe do que preocupa as disciplinas às quais faz referência, ou dos problemas que os distintos saberes se propõem na atualidade. E nem se fala diante da distância que existe entre o que se ensina na escola e os referenciais culturais cotidianos dos meninos e meninas ou dos adolescentes. (HERNÁNDEZ, 2000, p. 30).

Neste sentido, é importante a reflexão acerca de uma pedagogia crítica, que busque entender o papel do professor como o de um agente que almeja também uma formação política para o aluno a partir de metodologias e práticas que busquem envolver e trazer o contexto dos discentes para dentro de sala de aula. Posição esta asseverada por Gadotti (2012, p. 95):

Politizar o conteúdo não é tentar, a qualquer custo, ver na teorização do teorema de Pitágoras uma infiltração ideológica, é inserir Pitágoras historicamente e todos os 
teoremas e a própria matemática num contexto humano e social, em que os números e a abstração matemática têm um sentido.

Assim, a politização do conteúdo, ou seja, a aproximação deste com o cotidiano do aluno, incide em um processo de politização desse mesmo aluno. Importante sublinhar que se utiliza aqui o termo "politização" como referência ao sentido original do vocábulo política (ARENDT, 2011), como a atividade social desenvolvida pelos homens da polis grega, referenciando, assim, os processos atinentes ao desenvolvimento da consciência do coletivo e da participação nos processos sociais daquela comunidade. Neste sentido, podemos fazer referência ao que Hernández chama de “compreensão crítica e performativa da cultura visual”, que pressupõe

pensar a respeito do visual em termos de significado cultural, das práticas sociais e das relações de poder em que estejam implicadas as imagens e as práticas de visualidade [...]; refletir sobre as relações de poder que se estabelecem e articulam-se por meio das imagens [...]; e considerar as representações da cultura visual como discursos que refletem práticas culturais. (HERNÁNDEZ, 2007, p. 79).

É principalmente a partir de nossa crença nesta educação crítica e performativa que apontamos a ideia da cultura visual mais como uma estratégia do que como um método. Lembrando que a palavra método vem do grego methodos, met'hodos e significa o "caminho para chegar a um fim", se entendêssemos a cultura visual apenas como um método seria o mesmo que vê-la seguir um caminho possível de ser percorrido pelos educadores em busca do interesse dos alunos na escola. O que, contraditoriamente, seria considerá-la, afinal, como mais uma "disciplina” (que já afirmamos não ser). Mas vê-la como estratégia é considerar que pode haver mais do que um caminho para abordar criticamente uma prática de visualidade que nos afeta ou que sentimos afetar um determinado grupo social. Nesta estratégia, o questionamento é sistemático e, normalmente, é frequente gerar (ainda) mais perguntas do que respostas. E isto, de algum modo, vai contra uma atitude tradicional da escola, que é a de as perguntas gerarem uma - e só uma - resposta, redonda e acabada, em suma, uma verdade final e indiscutível.

Dentro deste rol de produtos da cultura visual, os artefatos da cultura da mídia aparecem também com muita intensidade no cotidiano social, o que certamente produz efeitos nas maneiras de pensar e ser dos estudantes. Assim como aponta Kellner (2001, p. 9):

As narrativas e as imagens veiculadas pelos media fornecem os símbolos, os mitos e os recursos que ajudam a construir uma cultura comum para a maioria dos indivíduos em 
muitas regiões do mundo de hoje. A cultura veiculada pelos media fornece o material que cria as identidades pelas quais os indivíduos se inserem nas sociedades tecnocapitalistas contemporâneas, produzindo uma nova forma de cultura global.

No entanto, na grande maioria dos casos, os conteúdos da cultura visual não são inseridos nos currículos escolares, e em muitas circunstâncias é comum que os próprios educadores não entendam estes produtos como importantes para a vida dos alunos. De acordo com Hernández (2000, p. 43),

a educação para a compreensão da cultura visual [...] é o estudo e a decodificação desses produtos culturais mediáticos. Conhecimento que talvez não seja conveniente aprender na escola, se o que se persegue é que os indivíduos respondam indefesos diante da enxurrada mediática que lhes cai em cima.

$\mathrm{Na}$ verdade, um investimento educacional em cultura visual tem o potencial de preparar os alunos para uma interpretação mais cuidadosa e atenta do consumo simbólico a que são submetidos (em parte voluntária e em parte involuntariamente) na contemporaneidade.

Entender como cada produto mediático incide sobre a vida, os valores e a identidade de cada um é um propósito crucial que tem relação com a criação da autonomia do aluno. Pois, conforme indica Freedman (2006, p. 26), "a educação é um processo de formação da identidade porque mudamos à medida que aprendemos". Neste sentido, cabe ao educador instar o aluno a fazer uma série de indagações, como: qual os efeitos das imagens sobre mim? Em que medida essas imagens fazem parte da minha conformação de sujeito?

\section{Ensinar pela cultura visual: um manifesto em prol da cultura visual}

Por fim, o uso do termo pela aparece aqui em um terceiro sentido, de manifesto, de defesa de uma perspectiva alternativa, mas não substitutiva, na qual acreditamos e trabalhamos enquanto professores, artistas e profissionais dos media. O título "Ensinar pela cultura visual” também significa a defesa de uma educação que possa dar prioridade a esta dimensão fenomenológica da vida contemporânea, que não pode ser ignorada pelos profissionais da educação de hoje.

De acordo com Hernández (2000), tratar o tema da cultura visual pode aparentemente parecer uma abordagem da educação sob o ponto de vista dos "perdedores". Isso porque o ensino da cultura visual não está ligado a nenhum tipo de meta pragmática-positivista de crescimento, seria um tipo de conhecimento "aparentemente inútil” e pouco rentável a partir do ponto de vista da política. 
Falar de compreensão da cultura visual torna-se ridículo num momento em que o que parece contar são as guerras políticas e econômicas do mundo das comunicações, quando se trata de determinar quem vai controlar e colocar a seu serviço os benefícios do mercado da globalização, no qual seus interesses irão circular por todo o planeta sem travas nem concorrência. (HERNÁNDEZ, 2000, p. 27).

No entanto, esta visão aponta para uma miopia dos planificadores da educação, uma vez que, conforme já reiteramos, a escola, nos moldes curriculares tradicionais, só faz aumentar a distância entre o que se ensina e os referenciais culturais dos jovens. Certamente este é um dos motivos pelos quais a escola é vista como desinteressante por grande parte dos alunos.

No seu artigo intitulado $O$ que pode a educação aprender das artes sobre a prática da Educação, Elliot Eisner (2008) desenvolve uma instigante argumentação sobre como o ensino poderia ser pensado a partir de uma série de dimensões oriundas do campo da arte. Nos apontamentos finais, revela que hoje, mais do que nunca, as artes fornecem o tipo de material ideal para a educação no mundo, uma vez que

[...] as nossas vidas requerem cada vez mais a capacidade de tratar mensagens conflituosas, de fazer juízos na ausência de regras, de lidar com a ambiguidade, e de fabricar soluções imaginativas para os problemas que encontramos. $\mathrm{O}$ nosso mundo não se subjuga a respostas únicas corretas ou a soluções claras seccionadas para problemas. (EISNER, 2008, p. 15).

Para que entendamos a proposição, não há uma resposta/posição única, simples e fácil acerca do ocorrido. Não há simplismos nem regras, mas situações complexas que carecem de análises densas, críticas e plurais. Esta capacidade complexa de interpretação é uma das dimensões mais importantes do que a arte pode ensinar à educação em seus processos pedagógicos.

Conforme apregoa Hernández,

[...] muitos educadores podem encontrar na cultura visual um novo motivo para fazer pontes entre o conhecimento da certeza que lhes brinda o currículo compartimentalizado disciplinar e os saberes híbridos e transdisciplinares sobre os quais nos pusemos a pensar [...]. Entre a escolarização que coisifica o menino e a menina ou o jovem convertendo-lhe em aluno a quem consideram como sujeito, com biografia, medos, dúvidas, que se incorporam como parte do processo educativo (2005, p.28).

Entender a perspectiva rizomática da cultura visual (HERNÁNDEZ, 2005) e integrá-la na escola significa assumir uma posição de compreensão da lógica dos tempos atuais, dos pensamentos e 
práticas da pós-modernidade. A condição pós-moderna aponta para um processo de produção/construção colaborativa, em que ocorre quase um abandono da ideia de leitor/receptor, em função da visão de um agente interativo nos processos de produção/veiculação/consumo simbólicos, exatamente como foi colocado no início deste texto, como uma das perspectivas primordiais do campo de estudos da cultura visual. Além do mais, o campo da cultura visual, adequado à condição da pósmodernidade, atua no sentido do fim das grandes narrativas: fim da ideia de que existe uma grande história, uma grande verdade ou ainda uma história oficial. Ao proporcionar visibilidade às micronarrativas, narrativas do cotidiano, da margem, de histórias alternativas, auxilia na construção de uma nova perspectiva de história.

\section{Considerações finais}

Uma das questões mais importantes da cultura visual tem a ver com o relativismo, no sentido de que as culturas são híbridas, díspares e cada sujeito relata a sua história de uma maneira particular; é também um dos pilares da cultura visual, a partir das premissas advindas, principalmente, dos estudos culturais. Por fim, a cultura visual, ao enfocar a perspectiva do leitor, busca uma valorização da experiência, a ideia de formação enquanto sujeito. Tudo isso acaba por ser uma afronta à "cultura das certezas" e uma abertura para a dúvida, a relativização, o subjetivo, ou seja, uma outra maneira, mais flexível, de vermos e interpretarmos o mundo em que vivemos para a construção de "uma outra narrativa para a educação".

Para uma proposta realista e viável, em que a cultura visual possa, de fato, fazer parte dos currículos escolares, certamente serão necessárias algumas perspectivas totalmente novas, envolvendo, no mínimo, uma maior flexibilização e permeabilização da tradicional "estanquicidade das disciplinas", de modo que estas possam ser trabalhadas a partir de temas transversais; também se faz necessária uma ideia diferenciada acerca do tempo na escola, pois na grande maioria das vezes o tempo do aprendizado é diferente do tempo cronológico; e, finalmente, a disposição dos professores para uma mudança de paradigma, de postura, que valorize mais os processos que os resultados. Conforme explanou Eisner (2008), que a arte possibilite às práticas da educação um ensino com mais exploração, mais surpresa e menos controle, um ensino que favoreça mais a diferença que a padronização. E que um ensino pela cultura visual possa ser uma das estratégias para o alcance destes objetivos.

PERSPECTIVA, Florianópolis, v. 35, n. 4, p. 1196-1214, out./dez. 2017 


\section{Referências}

ARENDT, Hannah. O que é política. Rio de Janeiro: Bertrand Brasil, 2011.

BAUMAN, Zygmunt. Modernidade liquida. Rio de Janeiro: Zahar, 2001.

BOURRIAUD, Nicolas. Estética Relacional. São Paulo: Martins Fontes, 2009.

CASTELLS, Manuel. O poder da identidade. A Era da informação: economia, sociedade e cultura. 2. ed. São Paulo: Paz e Terra, 2000.

DELEUZE, Gilles; GUATTARI, Félix. Mil platôs: capitalismo e esquizofrenia. v.1. Rio de Janeiro: Editora 34, 1995.

DIAS, Belidson. O ivmundo da educação da cultura visual. Brasília: UnB, 2011.

EISENHAUER, Jennifer. Beyound Bombardment: Subjectivity, Visual Culture, and Art Education. Studies in Art Education, v. 47, n. 2, p. 155-169, 2006.

EISNER, Elliot.O que pode a educação aprender das artes sobre a prática da educação? Currículo sem Fronteiras. v. 8, n. 2, p. 5-17, jul.Idez. 2008.

FREEDMAN, Kerry. Enseñar la cultura visual. Currículum, estética y la vida social del arte. Barcelona: Octaedro, 2006.

GADOTTI, Moacir. Educação e poder: introdução à pedagogia do conflito. 16. ed. São Paulo: Cortez, 2012.

GIDDENS, Anthony. Modernity and self-identity. Cambridge, UK: Polity Press, 1991.

GIROUX, Henry A.; SIMON, Roger. Cultura popular e pedagogia crítica: a vida quotidiana como base para o conhecimento curricular. In: MOREIRA, António F.; SILVA, T. T. (Orgs.) Currículo, cultura e sociedade. São Paulo: Cortez, 2002. p. 93-124.

HERNÁNDEZ, Fernando. Cultura visual, mudança social e projeto de trabalho. Porto Alegre: Artes Médica Sul, 2000.

De qué hablamos cuando hablamos de la Cultura Visual? Educação e Realidade, Porto Alegre, n. 34, p. 9-34, jul./dez. 2005.

Catadores da cultura visual. Proposta para uma nova narrativa educacional. Porto Alegre: Mediação, 2007.

KELLNER, Douglas. Cultura da mídia. São Paulo: Edusc, 2001. 
LYOTARD, Jean-François. La condition postmoderne: rapport sur le savoir. Paris: Éditions de Minuit, 1979.

MIRZOEFF, Nicholas. Una introducción a la cultura visual. Barcelona: Paidós, 2003.

PAGLIA, Camile. Imagens Cintilantes: Uma viagem através da arte desde o antigo Egipto até Star Wars. Rio de Janeiro: Apicuri, 2014.

POPKEWITZ, Thomas. S. Educational research: Values and visions of social order. Theory and Research in Social Education, v. 6, n. 4, p. 20-39, 1978.

PROENÇA, Graça. História da arte. São Paulo: Ática, 2009.

ROSE, Gillian. Visual Methodologies: An introduction to the interpretation of visual materials. London: Sage Publications, 2001.

SANTOS, Arquimedes et. al. Educação pela arte: estudos em homenagem ao Dr. Arquimedes da Silva Santos. Lisboa: Livros Horizonte, 2000.

SOUSA, Alberto. Educação pela Arte e Artes na Educação (3 v.). Lisboa: Instituto Piaget, 2003. 
Education and contemporary practices of visuality: what it means, after all, to teach by visual culture

\begin{abstract}
This paper aims to continue a discussion on the possible relationships between the fields of education and Visual Culture, suggesting a bias that systematizes a kind of epistemology of visual culture. For this, we used as argumentative axis the idea of a teaching by Visual Culture, opposing to what would be a teaching of Visual Culture, building, from this term, three statements: the visual culture is an interdisciplinary field and therefore cannot be taught as a closed set of content; the Visual Culture can be understood as a kind of strategy to link the content of the School to the extracurricular daily lives of students; finally, a manifesto in defense of Education by Visual Culture. To support such discussions and proposals, we used theoretical perspectives from authors like Hernández (2000; 2005; 2007); Freedman (2006); Mirzoeff (2003); Eisner (2008); among others.
\end{abstract}

Keywords: Education. Visual Culture. Image; Visuality.

\section{Juliana Zanini Salbego}

E-mail: julianasalbego@unipampa.edu.br

Leonardo Verde Charréu

E-mail: leonardo.charreu@gmail.com

\section{Educación y prácticas contemporáneas de} visualidad: lo que significa, al final, enseñar con la cultura visual

\section{Resumen}

El presente texto tiene como objetivo continuar la discusión sobre las posibles relaciones entre los ámbitos de la educación y cultura visual, lo que sugiere un sesgo que sistematice una especie de epistemología de la cultura visual. Para ello, se utilizó como eje argumental la idea de una enseñanza para la Cultura Visual, a diferencia de lo que sería una enseñanza de la Cultura Visual, construyendo, a partir de este término, tres afirmaciones: que la cultura visual es un campo interdisciplinario y por lo tanto no puede ser enseñado como un conjunto cerrado de contenidos; la cultura visual se puede entender como una especie de estrategia para vincular el contenido de la escuela con la vida cotidiana extraescolar de los estudiantes; Por último, un manifiesto en defensa de la Educación a través de la Cultura Visual. Para apoyar este tipo de discusiones y propuestas, utilizamos las perspectivas teóricas de autores como Hernández (2000; 2005; 2007); Freedman (2006); Mirzoeff (2003); Eisner (2008); entre otros.

Palabras clave: Educación. Cultura Visual. Imagen; Visualidad.

Enviado em: 17/05/2016

Versão Final aprovada em: 27/04/2017

Aprovado em: 05/05/2017 